\title{
Respiratory syncytial virus infection is associated with an altered innate immunity and a heightened pro-inflammatory response in the lungs of preterm lambs
}

Fatoumata B Sow ${ }^{1 *}$, Jack M Gallup ${ }^{1}$, Subramaniam Krishnan², Andriani C Patera², JoAnn Suzich² and Mark R Ackermann ${ }^{1}$

\begin{abstract}
Introduction: Factors explaining the greater susceptibility of preterm infants to severe lower respiratory infections with respiratory syncytial virus (RSV) remain poorly understood. Fetal/newborn lambs are increasingly appreciated as a model to study key elements of RSV infection in newborn infants due to similarities in lung alveolar development, immune response, and susceptibility to RSV. Previously, our laboratory demonstrated that preterm lambs had elevated viral antigen and developed more severe lesions compared to full-term lambs at seven days post-infection. Here, we compared the pathogenesis and immunological response to RSV infection in lungs of preterm and full-term lambs.
\end{abstract}

Methods: Lambs were delivered preterm by Caesarian section or full-term by natural birth, then inoculated with bovine RSV (bRSV) via the intratracheal route. Seven days post-infection, lungs were collected for evaluation of cytokine production, histopathology and cellular infiltration.

Results: Compared to full-term lambs, lungs of preterm lambs had a heightened pro-inflammatory response after infection, with significantly increased MCP-1, MIP- $1 \alpha$, IFN- $\gamma$, TNF- $\alpha$ and PD-L1 mRNA. RSV infection in the preterm lung was characterized by increased epithelial thickening and periodic acid-Schiff staining, indicative of glycogen retention. Nitric oxide levels were decreased in lungs of infected preterm lambs compared to full-term lambs, indicating alternative macrophage activation. Although infection induced significant neutrophil recruitment into the lungs of preterm lambs, neutrophils produced less myeloperoxidase than those of full-term lambs, suggesting decreased functional activation.

Conclusions: Taken together, our data suggest that increased RSV load and inadequate immune response may contribute to the enhanced disease severity observed in the lungs of preterm lambs.

Keywords: Lung, neonate, premature infant, immune response, RSV, lamb

\section{Introduction}

Respiratory syncytial virus (RSV) is the most common cause of severe lower respiratory tract disease in children, with the highest morbidity occurring in the youngest infants [1-3]. Preterm infants are particularly susceptible to the disease, due in part, to their immature

\footnotetext{
* Correspondence: fsow@yahoo.com

'Department of Veterinary Pathology, College of Veterinary Medicine, lowa

State University, Ames, IA 50011, USA

Full list of author information is available at the end of the article
}

immune system, low birth weight, and lung immaturity. Recent literature suggests that infants born 33-35 weeks of gestation are at similar risk for RSV-related lower respiratory tract infection as infants born less than 32 weeks of gestation (reviewed in [4]). RSV-related hospitalization rates of infants born at 33-35 weeks of gestation are twice as high as those of term infants [5]. Currently, there is no RSV vaccine, and the only preventive treatment for the disease involves passive immunization with antibody against RSV $[3,6]$. 
The pathogenesis of RSV disease is not well understood; however, a multifactorial process that includes virus-induced pathology and a concomitant exaggerated host immune response may play critical roles in the disease process $[7,8]$. Increased viral load is thought to contribute to the severity of disease [9], although the underlying mechanisms responsible for increased viral replication in some individuals are not completely understood. RSV specific immunity is also believed to be involved in the mechanism of severe lower respiratory tract disease, based on experiences with a formalininactivated RSV vaccine preparation during which vaccinated infants developed an enhanced eosinophilia to reinfection $[10,11]$.

Previously, our laboratory has shown that preterm lambs infected with bovine RSV (bRSV) developed clinical symptoms and lesions that paralleled the course of disease observed in human infants suffering from severe RSV disease [12]. Moreover, they had a reduced capacity for RSV antigen clearance compared to full-term lambs [12]. The precise mechanisms underlying the age-dependent disease severity and the lack of RSV clearance were not investigated. Therefore, we studied the relationship between developmental age and immunological competence in response to RSV infection by assessing for differences in the nature of the inflammatory response in the lungs of preterm and full-term lambs. We hypothesized that the increased viral load in preterm lambs is associated with an altered distribution and functional activation of immune cells and increased lung pathology that differs from full-term lambs.

\section{Materials and methods \\ Animals}

Animal use and experimental procedures were approved by Iowa State University's Animal Care and Use Committee. We used banked lung samples from lambs that were used in another study to characterize bRSV infection in the lamb model [12]. Briefly, lambs were delivered preterm by Caesarian section at 138 days of gestation (term is 147 days) or full-term by natural birth. Both groups were inoculated with bRSV strain $375\left(20 \mathrm{ml}\right.$ at $\left.10^{3-4} \mathrm{TCID}_{50} / \mathrm{ml}\right)$ or sterile cell growth media $(20 \mathrm{ml})$ via the intratracheal route. Lambs ( $\mathrm{n}=6$ for the preterm control group, $\mathrm{n}=6$ preterm RSV, $\mathrm{n}=3$ full-term control, $\mathrm{n}=5$ full-term RSV) were euthanized with sodium pentobarbital i.v. 7 days post-infection. Sections of the right middle lung lobe were removed, snap-frozen in liquid nitrogen and stored at $-80^{\circ} \mathrm{C}$ for real-time RT-PCR and other functional assays. Additional sections of the right cranial lung lobe were fixed in 10\% neutral-buffered formalin for histopathology and immunohistochemical analyses.

\section{Histopathology, lesions and staining scores}

After formalin fixation, lung samples were embedded in paraffin blocks. Lung sections $(5 \mu \mathrm{m})$ were stained with $\mathrm{H} \& \mathrm{E}$ to assess histologic changes, including cellular infiltration and epithelial alterations. Cellular infiltration and epithelial hyperplasia were described and scored by a pathologist (MRA) using a minimum of three $20 \mathrm{X}$ fields in each lung section.

The extent of neutrophil infiltration in bronchioles and alveoli surrounding affected bronchioles in the 20X fields were scored with the following scale: $0=$ no significant neutrophil infiltration, 1 = detectable presence of 1 to 5 neutrophils within bronchioles/alveolar lumens in $20 \mathrm{X}$ field, 2 = groups (greater than 5 ) of cells in bronchioles/alveolar lumens in 20X field, 3 = accumulation of cells that fills bronchioles/alveolar lumens in 20X field, 4 = dense infiltration of cells that distends bronchiolar and alveolar lumens in a 20X field. Macrophage infiltration was determined using the same scoring system.

Lymphocytes and plasma cell infiltration into the alveolar and bronchiolar institium were scored with the following scale of $20 \mathrm{X}$ fields: $0=$ no significant infiltration, 1 = presence of infiltrating cells in alveolar septa or bronchiolar interstitium, 2 = accumulation of several cells within alveolar septa or bronchiolar interstitium, 3 = accumulation of cells that expands the alveolar septa or bronchiolar interstitium, 4 = accumulation of cells that forms dense aggregates in the alveolar septum or bronchiolar interstitium.

With delivery of RSV inoculum in this study, lesions were present within distal bronchioles and alveoli [12]. In contrast, bronchi and large proximal bronchioles lack lesions and RSV antigen. Thus only distal bronchioles were scored for epithelial alterations and these airways were relatively uniform in size and diameter. Bronchiolar epithelial hyperplasia was scored with the following scale: 0 = no lesion, 1 = first detectable thickening resulting in mild hypertrophy of bronchiolar cells and occasional cells more than one layer thick, 2 = thickening that is double the normal thickness of a single cuboidal cell, 3 = thickening that protrudes into and partially occludes the airway lumen and slight expansion/distension of the airway, $4=$ thickening that occludes the airway lumen resulting in a very narrow (slit) lumen and marked distension of the airway.

Lung sections were also stained with periodic acidSchiff (PAS) to assess the stage of epithelial differentiation/maturity as a measure of glycogen retention in type II pneumocytes. The thickened epithelial layers had variable levels of staining avidity, and ten alveoli were scored per lung section from each lamb. Alveoli were similar in size which ranged between 100-200 $\mu \mathrm{m}$ in diameter. Scoring was based on predetermined scale: 0 , 
no detectable stain; 1 , faint but detectable stain; 2, cytoplasmic staining present in less than $30 \%$ of alveolar epithelial cells; 3 , cytoplasmic staining present in more than $60 \%$ of alveolar epithelial cells.

\section{RNA isolation and one-step real-time reverse transcriptase qPCR}

Total RNA was isolated from lung tissue as previously described [13] using a procedure based on TRIzol reagent (Invitrogen, Carlsbad, CA). The RNA samples were DNase-treated using TURBO DNase (TURBO DNA-free kit, Ambion, Austin, TX). RNA concentrations and purity were measured by absorbance readings at $260 \mathrm{~nm}$ and $280 \mathrm{~nm}$.

Initial RT-qPCR analysis involved running a test plate for each target to identify the best RNA dilution ranges in which PCR inhibition was not observed, and where amplification efficiencies were better than $80 \%$. Testplate set-up parameters and analysis were performed using PREXCEL-Q [14]. RNA samples were used at $0.784 \mathrm{ng} / \mu \mathrm{l}$ in fluorogenic one-step real-time qPCR reactions. Each $20 \mu \mathrm{l}$ reaction contained $4.8 \mu \mathrm{l}$ of RNA sample, $775 \mathrm{nM}$ primers, $150 \mathrm{nM}$ TaqMan hydrolysis probe (5'-6FAM, 3'-TAMRA-quenched or 5'-6FAM, 3'MGBNFQ), nuclease-free water, $5.5 \mathrm{mM} \mathrm{MgSO}_{4}$, SuperScript III RT/Platinum Taq mix (Invitrogen), and Onestep reaction mix with ROX (Invitrogen). Primers and probes sequences for all targets except perforin can be found in $[13,15]$. Sequences for perforin are: Fwd: 5'-GC CGTGAGTAAGTATGTGACTGACA; Rev: 5'-GCCAG GACACATGCATTGG; Probe: 6FAM-TGGAGGG ACTGCAACC-MGBNFQ). The samples were placed in duplicate wells of 96-well plates (Eppendorf, Westbury, NY). No-template control (NTC) and no-reverse transcriptase (NRC) reactions consistently demonstrated lack of target contamination and negligible genomic DNA contamination. The GeneAmp 5700 Sequence Detection System (Applied Biosystems) was programmed for thermocycling at $15 \mathrm{~min} 55^{\circ} \mathrm{C}, 2 \min 95^{\circ}$ $\mathrm{C}$, and 50 cycles of $15 \mathrm{~s} 95^{\circ} \mathrm{C}, 30 \mathrm{~s} 58^{\circ} \mathrm{C}$. Quantification cycle $(\mathrm{Cq})$ values generated by the GeneAmp 5700 system were further assessed using custom Excel files employing the efficiency-corrected standard curve-based relative quantification (Pfaffl) approach for qPCR [16]. Results are expressed as gene (mRNA) expression of infected samples relative to that of uninfected samples.

\section{Immunohistochemistry (IHC) and scoring system for myeloperoxidase and caspase 3}

Sections were made from paraffin-embedded blocks on the same day and were stained for either myeloperoxidase or caspase 3 in a single batch for uniformity. Briefly, paraffin-embedded lung sections were deparaffinized, blocked in $10 \%$ normal goat serum $+10 \%$ normal swine serum in PBS, then stained with 1:300 rabbit antihuman myeloperoxidase (Dako, Carpinteria, CA) or 1:1000 rabbit anti-human/mouse active caspase 3 (R\&D Systems, Minneapolis, MN) followed by 1:300 biotinylated goat anti-rabbit IgG (Kirkegaard \& Perry Laboratories, Gaithersburg, MD), streptavidin-conjugated horseradish peroxidase (BioGenex) and Nova Red (Vector, Burlingame, CA). Finally, the slides were counterstained with Harris' hematoxylin. Scoring for myeloperoxidase $(\mathrm{MPO})$ were made in $40 \times$ sections from at least 3 fields per lung lobe per animal where 0 $=$ no staining, $1=1-10 \%$ of neutrophils had $\mathrm{MPO}$ immunoreactivity (IR; MPO-IR), $2=11-30 \%$ of neutrophils had MPO-IR; $3=30-60 \%$ of neutrophils had MPO-IR and $4=>60 \%$ of neutrophils had MPO-IR. Scores for caspase 3 IR ranged from 0-4 and were assigned to bronchiolar and alveolar areas. In bronchioles: $(0=$ no staining, $1=1-10 \%, 2=11-30 \%, 3=30$ $60 \%, 4=$ more than $60 \%$ of airway epithelia had immunoreactivity to caspase 3 ). In alveoli, staining occurred in consolidated areas, containing lymphocytes, plasma cells, macrophages and alveolar epithelia: $(0=$ no staining, $1=1-10 \%, 2=11-30 \%, 3=30-60 \%, 4=$ more than $60 \%$ of consolidated areas had immunoreactivity to caspase 3).

\section{Lung nitrite levels}

Lungs were homogenized in a Tissue Protein Extraction Reagent (T-PER; Fisher Science, Hanover Park, IL) at a ratio of $1 \mathrm{~g}$ tissue $/ 20 \mathrm{ml}$ T-PER. After the addition of protease inhibitors cocktail tablets (Roche), the samples were homogenized using an Omni $\mathrm{TH}$ homogenizer (Omni International). Protein concentration was determined using the Coomassie Plus Protein Assay Reagent (Fisher). Nitrite levels in lung homogenates were measured using a commercially available Griess reaction assay kit as per the manufacturer's instructions (Promega, Madison, WI). The optical density at $550 \mathrm{~nm}$ $\left(\mathrm{OD}_{550}\right)$ was measured using a microplate reader. Nitrite concentrations were calculated by comparison with the $\mathrm{OD}_{550}$ of standard solutions of sodium nitrite.

\section{Lung arginase activity}

Arginase levels in lung homogenates were measured using a commercially available assay (QuantiChrom arginase assay kit by BioAssay System, Hayward, CA). Methods followed the manufacturer's recommendations. Arginase activity (units/L) in all lung samples was calculated by comparison with the $\mathrm{OD}_{520}$ of standard solution of urea.

\section{Statistical analysis}

The results were analyzed by one-way ANOVA using SAS version 9.1 (SAS Institute, Cary, NC). Mean values 
of relative mRNA expression levels of control animals and RSV-infected animals were compared at $\mathrm{p}<0.05$, *** $\mathrm{p}<0.01$, and $* * \mathrm{p}<0.001$ and expressed as means \pm SE.

\section{Results}

RSV infection induces higher relative mRNA levels of innate immune mediators in preterm lambs than full-term lambs

Previously, our laboratory demonstrated that the bRSV challenge dose used to infect lambs caused clinical signs and pulmonary lesions typical of severe human RSV disease [12]. Moreover, we reported that preterm lambs had enhanced viral load in their lungs compared to full-term lambs [12]. In order to compare the immune response during RSV infection across age groups in lambs, we measured the expression of several key innate immunity mediators at the mRNA level. Levels of MIP-1 $\alpha$, MCP-1, IL-8, TNF- $\alpha$, IFN- $\gamma$ and IL-10 (Figure 1A-F) were significantly increased in RSV-infected animals compared to control animals of the same age group. Full-term lambs infected with RSV had statistically significant enhanced expression of MIP- $1 \alpha$, MCP-1, IL- 8 and IFN- $\gamma$, but no significant changes in the expression of TNF- $\alpha$ and IL-10 when compared to control animals of the same age group. Comparisons across age groups following infection revealed that expression of MIP-1 $\alpha$, MCP-1, IL-10, TNF- $\alpha$ and IFN- $\gamma$ were significantly increased by infection in preterm lambs compared to full-term lambs. These results suggest that an inadequately enhanced immune response occurs in the lungs of preterm lambs after RSV infection.

RSV infection is associated with airway structural changes and increased caspase 3 staining in preterm lambs

During infection, epithelial cell injury occurs and is associated with proliferation of nearby epithelia to replace injured cells (epithelial cell thickening/hyperplasia). Consistent with this, we determined that control lambs of either age group lacked lesions and areas of epithelial hyperplasia at 7 days post-inoculation with

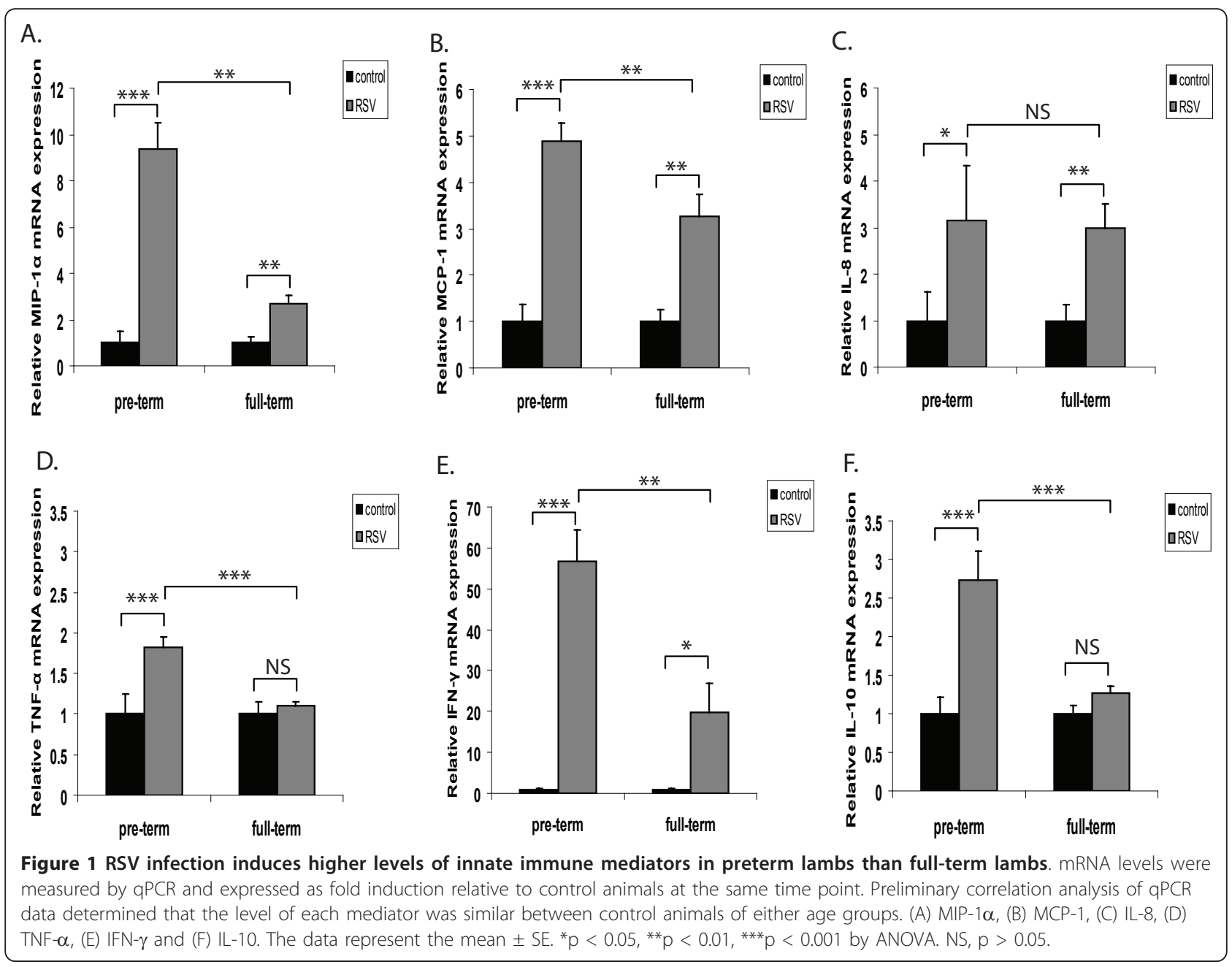


medium. However, 7 days post RSV infection, variable degrees of thickening of the epithelial lining were present in multifocal bronchioles of preterm (long arrows in Figure 2A), and to a lesser degree, full-term lambs (Figure 2B). This was due to hyperplasia of the bronchiolar epithelium with the presence of occasional mitotic figures (short arrow; Figure 2A) and formation of occasional syncytial cells (data not shown). The epithelial cells were cuboidal to polygonal and formed one to several layers in thickness. Epithelial cells in the

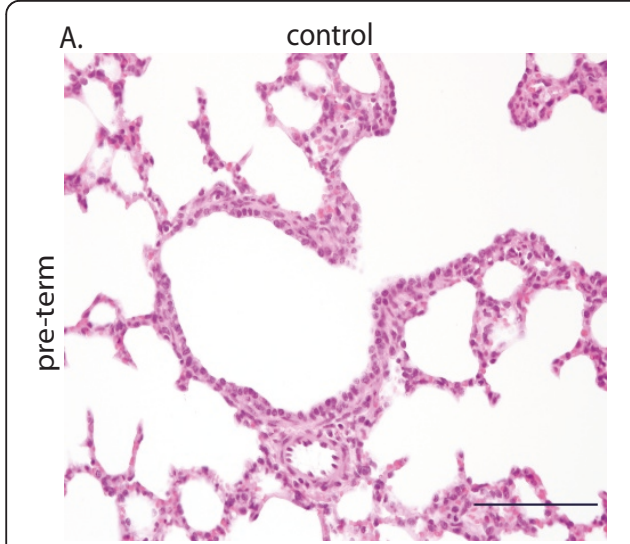

C.
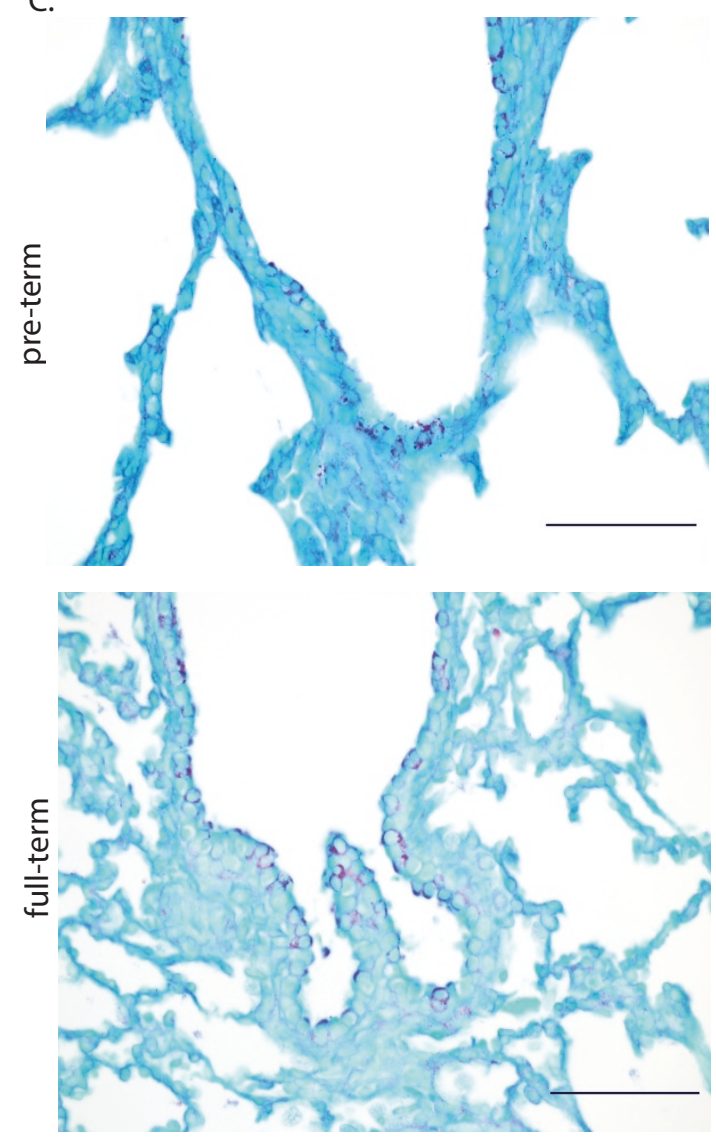

RSV

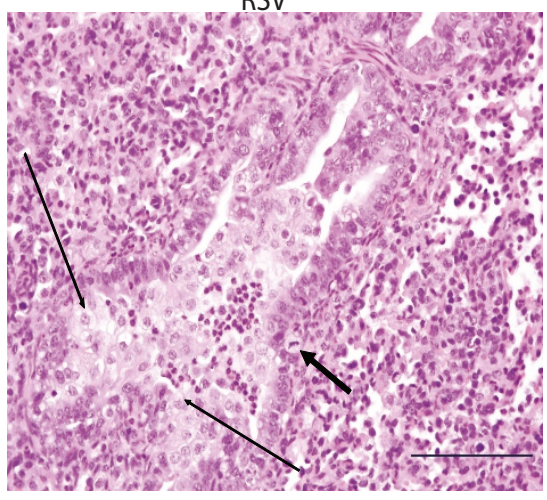

B.

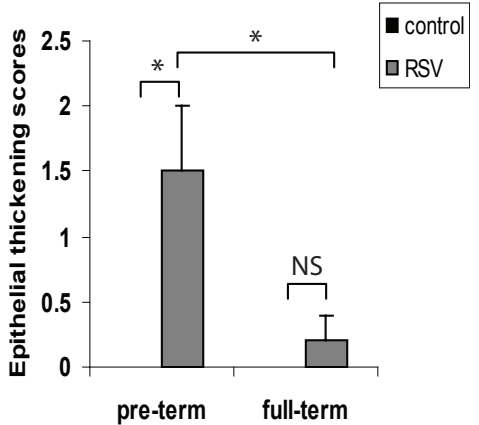

RSV
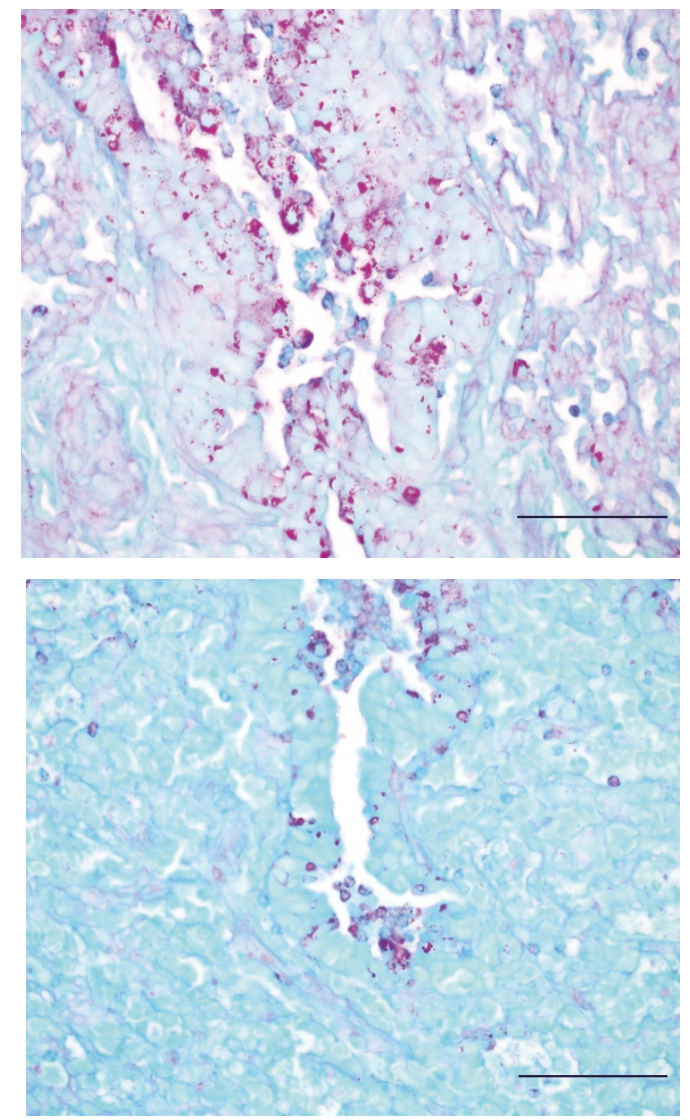

Figure 2 RSV infection is associated with airway structural changes in the preterm lung. (A) Representative H\&E stain of lung sections from control preterm lamb and RSV-infected preterm lamb. Long arrows represent epithelial thickening, and the short arrow represents a mitotic figure. Bars = $200 \mu \mathrm{m}$. (B) Lung sections from each animal were stained with H\&E, and epithelial thickening (epithelial cell proliferation/ hyperplasia) was scored (see materials and methods section for scoring system). (C) Representative Periodic Acid Schiff (PAS) stain of lung sections from preterm and full-term lambs comparing control to RSV-infected groups. Lung sections were examined under a 20X field. Bars = $200 \mu \mathrm{m}$. The data represent the mean \pm SE. ${ }^{*} p<0.05$ by ANOVA. NS, $p>0.05$. 
areas of extensive epithelial thickening were associated with intense staining for PAS (Figure 2C), indicating increased glycogen retention and cellular immaturity. Lungs of RSV-infected preterm lambs had significantly more $\mathrm{PAS}^{+}$cells than those of RSV-infected full-term lambs (Figure 2C). However, a decrease in epithelial PAS staining was observed during maturation of lung, independent of infection (Figure 2C). This finding, which is consistent with published data comparing the distribution of $\mathrm{PAS}^{+}$cells through ontogeny in the ovine lung [17], suggests that preterm birth and RSV infection may be independent factors that contribute to the increased epithelial glycogen retention.

In addition to the epithelial hyperplasia, pulmonary microscopic lesions were present in RSV-infected animals (Figure 3A). These lesions were similar in both preterm and full-term lambs, but were often accentuated in the preterm lambs. Briefly, multifocal bronchioles of all lambs contained variable infiltrates of neutrophils, occasional degenerate epithelial cells and cell debris with occasional macrophages. Alveolar lumens around these bronchioles had increased numbers of alveolar macrophages with cell debris and small amounts of seroproteinaceous fluid. Infiltrates of lymphocytes and plasma cells were present in alveolar septa and around bronchioles in the bronchiolar adventitia and, to a lesser degree, in the bronchiolar lamina propria (Figure 3A). The observed lung pathology is consistent with RSV infection and has been similarly described in RSVinfected humans [18], cattle (reviewed in [19]) and lambs [12,20-22].

To assess the apoptotic response, lung caspase 3 expression was detected by immunohistochemistry (IHC). Caspase 3 immunoreactivity (IR) was seen in alveolar areas of both groups of infected lambs. However, alveoli of RSVinfected preterm lambs had significantly enhanced IR to caspase 3 when compared to full-term lambs (Figure 3B). A similar trend and level of caspase 3 IR was also observed in bronchioles of infected lambs (Figure 3C). The enhanced viral load observed in lungs of preterm lambs may contribute to the pro-apoptotic response observed.

\section{Neutrophils of RSV-infected preterm lambs have reduced myeloperoxidase levels compared to full-term lambs}

The primary RSV infection in infants is characterized by a strong neutrophil influx into the airways [23-25]. Increased numbers of neutrophils were also detected in lungs of preterm and full-term RSV-infected lambs compared to control lambs (Figure 4A). We also assessed the levels of myeloperoxidase, a key constituent of neutrophils cytotoxic armament [26], by IHC in lung sections. RSV infection was associated with myeloperoxidase IR in both preterm (Figure 4B) and full-term (Figure 4C) lambs when compared to control lambs of the same age groups. However, comparisons across age groups revealed that myeloperoxidase IR was significantly reduced in preterm lambs infected with RSV compared to full-term lambs infected with RSV (Figure 4D). MPO levels in control lambs of either age group were minimal to non-detectable because there were few neutrophils in lung sections from those animals. As neutrophils from myeloperoxidase-deficient individuals kill microorganisms poorly $[27,28]$, our results suggest that neutrophils from RSV-infected preterm lambs may have reduced functionality compared to RSV-infected full-term lambs.

\section{Macrophages from preterm lambs are recruited to the lung after infection, but produce less nitric oxide than infected full-term lambs}

Because preterm lambs have increased viral loads in the lung [12], we hypothesized that antigen presenting cells, in particular macrophages, were not effectively recruited to the lungs. However, histological analysis of lung sections from preterm lambs in this study indicated that macrophage infiltration was significantly increased by infection when compared to uninfected animals (Figure $5 \mathrm{~A})$. In full-term lambs the differences in macrophage numbers between control and infected lungs were not statistically significant (Figure 5A). These findings suggest that the inability of preterm lambs to clear virus from their lungs was not dependent on macrophage numbers.

Since macrophage numbers were similar between preterm and full-term lambs, we reasoned that the functional activity of macrophages of preterm lambs might differ. Whereas the generation of nitric oxide is a hallmark of classically activated macrophages, the phenotype of alternatively activated macrophages includes induction of arginase 1 and reduced levels of nitrate (reviewed in [29]). We measured levels of nitrite, a stable breakdown product of nitric oxide, and arginase in lung homogenates from both groups of lambs. While full-term animals displayed an increase in nitrite levels in their lungs following infection, those of preterm animals were significantly reduced by infection (Figure 5B). No significant changes in arginase levels were measured in either group of lambs regardless of RSV infection (Figure 5C). These findings suggest that macrophages are recruited following RSV infection, but have an altered functional state in the preterm lung.

\section{Lungs from infected preterm lambs display similar trends in lymphocytic infiltration and functional state compared to full-term lambs}

Scoring for lymphocytes and plasma cell infiltration revealed that RSV infection induced comparable cellular recruitment in the lung in both preterm and full-term lambs (Figure 6A). The functional state of the 


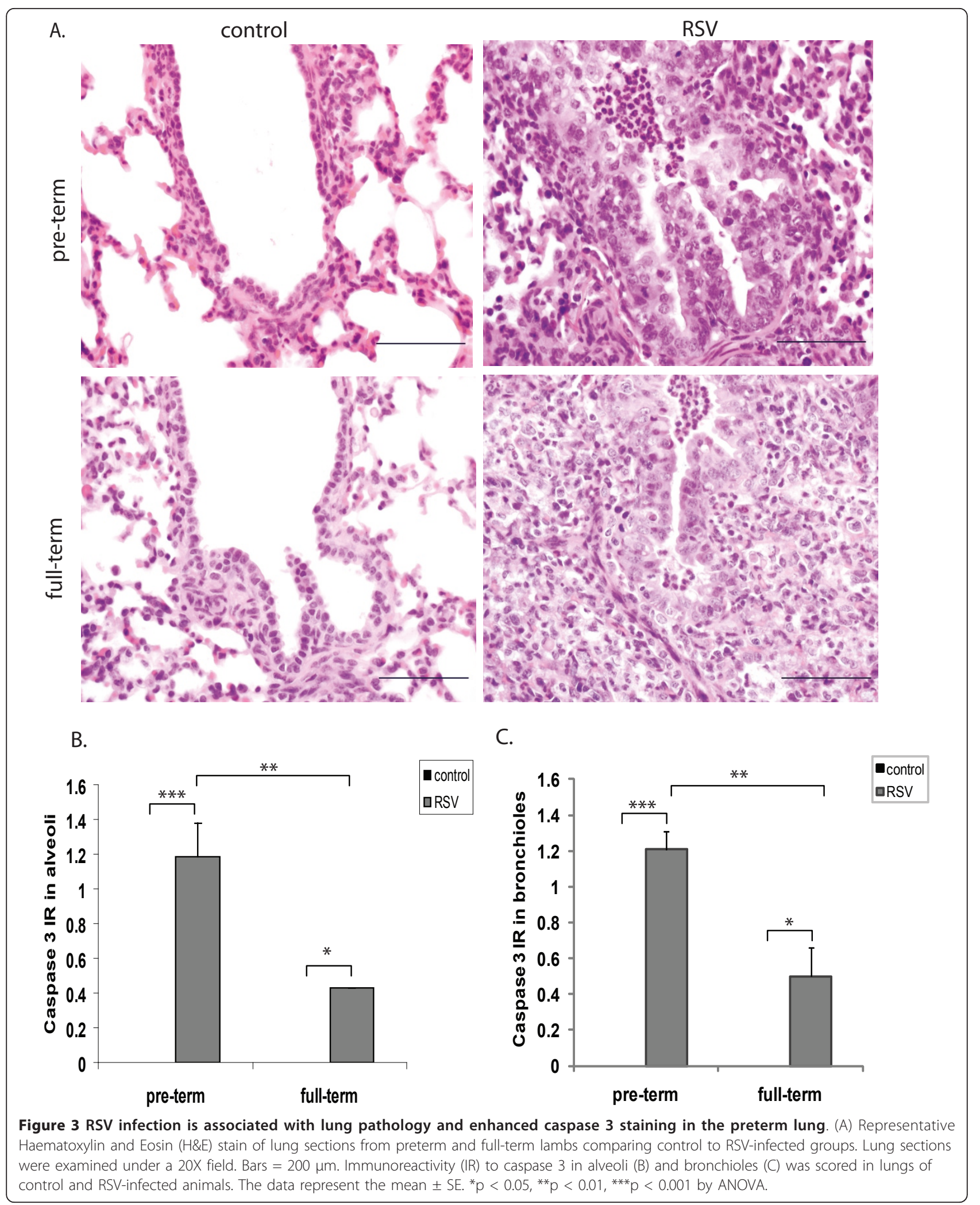


A.

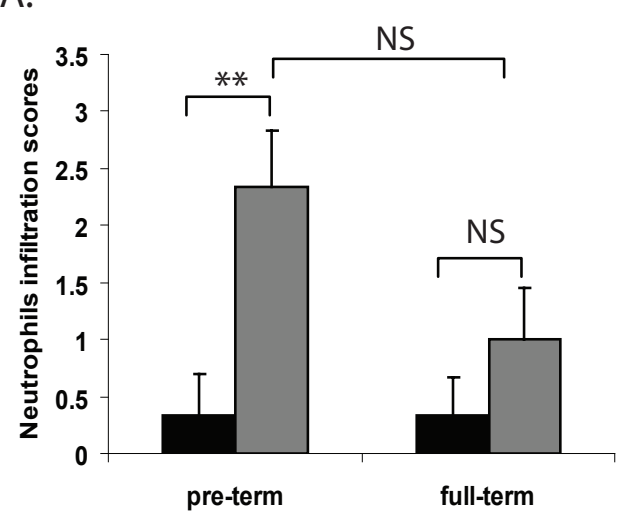

B.
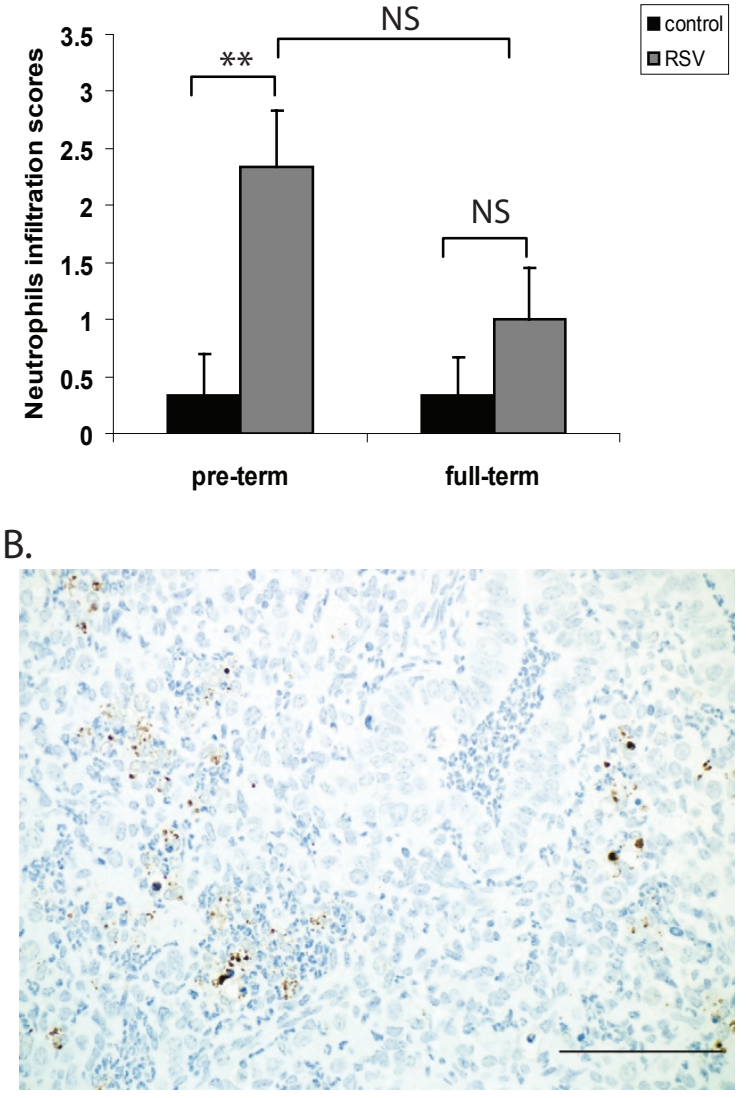

D.

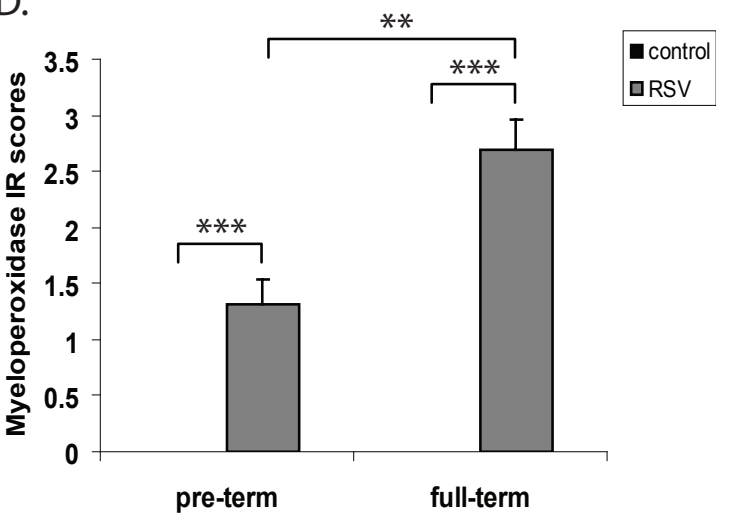

C.

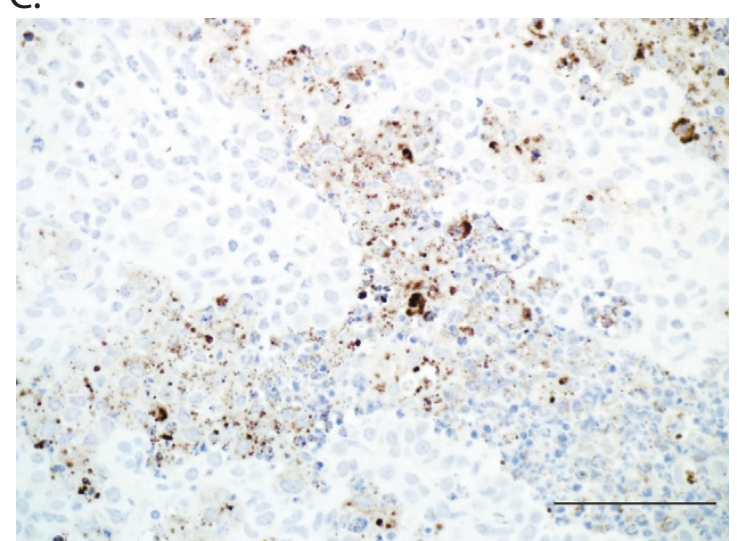

Figure 4 Neutrophils of RSV-infected preterm lambs have reduced myeloperoxidase levels compared to full-term lambs. (A) Scoring of neutrophil infiltration in the lung sections of each animal. Histochemical analysis of myeloperoxidase expression in lungs of (B) RSV-infected preterm lambs and (C) RSV-infected full-term lambs. (D) Scores were assigned in lungs of control and RSV-infected animals based on IR to myeloperoxidase. The data represent the mean \pm SE. ${ }^{* *} p<0.01,{ }^{* *} p<0.001$ by ANOVA. NS, $p>0.05$. Bars $=100 \mu \mathrm{m}$.

lymphocytes was assessed through perforin mRNA (Figure 6B), whose levels were induced by RSV. Similar to the cellular infiltration, perforin mRNA was induced at comparable levels regardless of the age of the infected animal (Figure 6B). The expression of PD-L1, a negative regulator of $\mathrm{T}$ cell function was also measured: RSV infection significantly induced PD-L1 mRNA expression in both groups of lambs. However, a comparison between age groups showed that PD-L1 levels in RSVinfected preterm lambs were significantly higher than in RSV-infected full-term lambs (Figure 6C). Taken together, these results suggest that lymphocytic function may be further reduced in preterm lambs than full-term lambs.

\section{Discussion}

Given that infants born prematurely are at higher risks of severe lower respiratory infections with RSV [30,31], we sought to identify potential factors responsible for the age-dependent susceptibility to this pathogen. In this study, we extended characterization of our preterm lamb RSV-infection model [12] by more thoroughly evaluating the immunological aspects of the disease. Herein, we have provided data indicating that during RSV infection, preterm lambs have a heightened innate immune response associated with significant airway structural changes and defects in the distribution and activation of immune cells crucial to host defense against RSV. These responses were less pronounced in full-term lambs. The inappropriate immune response observed in preterm lambs could be attributed to the enhanced viral load in the lungs or to the role for developmental age in mounting an appropriate anti-RSV response. Correlation analysis of the qPCR data showed that the expression of all targets assessed in this study did not differ in lungs of either uninfected preterm and full-term lambs (data not shown).

The recognition of RSV by pathogen-associated molecular patterns by PRRs such as TLRs and RIG-1 [32] results in a cascade of signaling events mediated by NF- 

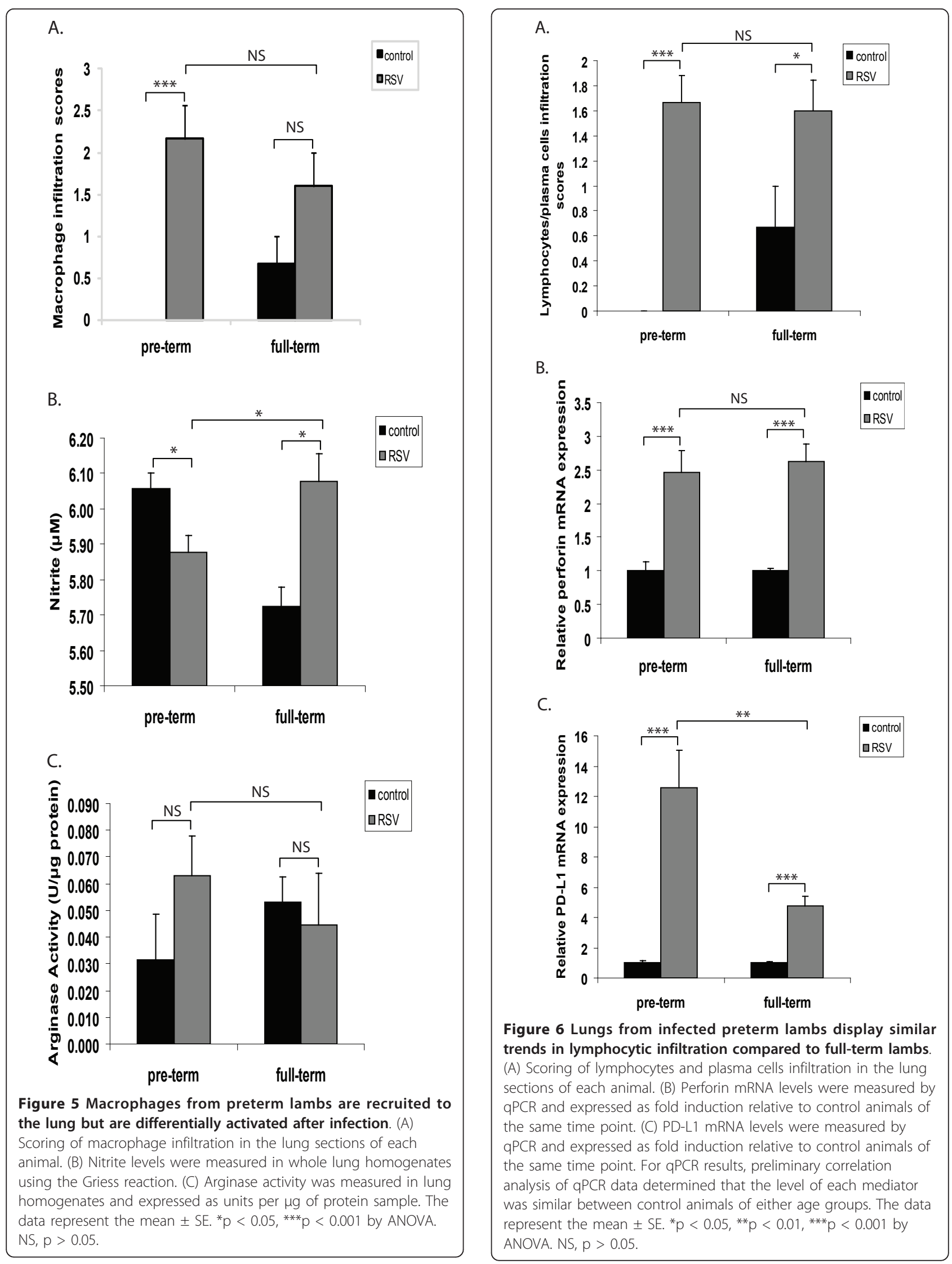
$\kappa \mathrm{B}$. During an infection with RSV, these signaling events lead to the expression of cytokines and chemokines, which mediate pro-inflammatory functions to recruit and activate cells, but also regulate the pro-inflammatory state (reviewed in $[33,34])$. In the current study, RSV-infected preterm lambs had a heightened proinflammatory response in their lungs compared to fullterm lambs. The observed heightened levels of MIP-1 $\alpha$, MCP-1, IFN- $\gamma$, TNF- $\alpha$ and IL-10 in RSV-infected preterm lambs may be due to the increased viral load observed in that group of animals, or to age-related inappropriate transcriptional regulation that contributes to increased pathology, reduced viral clearance, and enhanced disease severity.

RSV predominantly infects airway epithelial cells, which form the first line of defense against the virus and are the site of disease-associated inflammation. RSV infection of preterm lambs was associated with changes in the bronchiolar epithelium, characterized by significant epithelial thickening and increased presence of PAS staining in epithelial cells. At present, it is unclear whether the epithelial thickening and the increased PAS staining detected in the preterm lambs are due to increased RSV replication, to enhanced levels of immune mediators in the lambs, or a combination of both. It is likely that the epithelial thickening, the intra-airway inflammation and bronchoconstriction due to inflammation partially obstruct the bronchiolar lumen and impairs airflow in the preterm lung. Such changes would contribute to impaired gaseous exchange. Additional studies on physiological measurements of airflow and gas exchange would provide important information on the disease process.

Cellular mediators of inflammation, including neutrophils, macrophages, T cells, B cells and eosinophils play key roles in RSV disease in humans (reviewed in [35]). Our findings suggest that these mediators are also involved in the immune response triggered by RSV in lambs. Primary RSV infection in infants is characterized by a strong neutrophil influx [23-25]. In lambs, the neutrophil influx in the airways suggests that these cells might be important contributors to RSV disease. Reports in the literature describing the neutrophil defense system in humans at birth have determined that the neutrophil response is immature and functionally suboptimal $[36,37]$. Our current study is consistent with these reports in that, despite similar neutrophil infiltration at the site of infection, neutrophils from preterm lambs had significantly lower myeloperoxidase levels than full-term lambs following RSV infection. In addition, the ratio of myeloperoxidase IR to neutrophil infiltration scores (0.56 in preterm lambs, compared to 2.7 in full-term lambs) suggests that the levels of myeloperoxidase per neutrophil is greater in the full-term lambs.. In accordance with our findings, myeloperoxidase levels are significantly reduced in infants born prematurely, but not in term neonates (reviewed in [38]). In addition to prematurity, it is likely that the inappropriate immune response, concomitant with the enhanced viral load in the lung, play a role in modulating myeloperoxidase levels in neutrophils in preterm lambs. To our knowledge, this is the first study to report the role of RSV infection on myeloperoxidase levels during primary infection in preterm lambs.

Although macrophages were recruited to the lungs of both preterm and full-term lambs following RSV infection, the decreased nitrite levels and the trend towards increased arginase activity in lungs of infected preterm lambs suggest that macrophages are either immature or differentially activated in the preterm lung infected with RSV. Alternatively activated macrophages also fail to produce nitric oxide through the induction of arginase and are unable to efficiently kill intracellular pathogens (reviewed in [39]). Based on nitrite levels and arginase activity, our data indicates that macrophages in the RSV-infected preterm lung may have a sub-optimal activation state, resulting in an ineffective immune response to viral infection and poor viral clearance. In addition, our finding that RSV-infected preterm lambs have enhanced caspase 3 IR is in agreement with a study of infants' lungs with fatal lower respiratory tract illness caused by RSV [40]. In the preterm lung, these apoptotic cells are probably not cleared by the macrophages, thus contributing to an inappropriate immune response for viral clearance.

RSV infection can dysregulate RSV-specific cytolytic T cells expression and suppress memory development in the respiratory tract. A rapid loss of RSV-specific memory $\mathrm{CD}^{+}$cells in the lungs after infection has been noted in mice (reviewed in [41]). In addition, RSV has been reported to inhibit the development of cytotoxic responses in vivo, by suppressing CD4 lymphocyte function [42], interfering with antigen-dependent $\mathrm{T}$ cell receptor signaling [43], or inducing lymphocyte apoptosis [44] among other mechanisms. Although we observed no significant differences in lymphocytic infiltration or in the expression levels of components of the lymphocyte lytic machinery (perforin/granzyme) in this study, RSV infection significantly induced the expression levels of PD-1 (data not shown) and PD-L1 in the ovine lung. Because the PD-1/PD-L1 pathway plays an important role in regulating $\mathrm{T}$ cell exhaustion [45-48], it is conceivable that other functional aspects of $\mathrm{CD}^{+}$cells, such as their capacity to degranulate, are impaired in the RSV-infected ovine lung.

There appears to be a correlation between degrees of cellular infiltration and chemokine levels between preterm and full-term lambs. Similar levels of neutrophils are present in the infected lungs of both preterm and 
full-term lambs, which correlate with similar levels of IL-8 in the two groups of infected lambs. In the absence of infection, lungs of lambs of either age group have little to no macrophage infiltration. However, in response to RSV infection, the relative increase above baseline in lung macrophage numbers appears to be higher in preterm lambs (infiltration scores of 0 to 2.17 in preterm lambs compared to infiltration scores of 0.67 to 1.6 in full-term-lambs). This is consistent with overall higher levels of MCP-1 and MIP- $1 \alpha$ following infection in preterm lungs and a relatively greater elevation in these mediators compared with uninfected baseline levels (for MCP-1: 4.88-fold increase in preterm compared to 3.26fold in full-term; for MIP-1 $\alpha$ : 9.4-fold increase in preterm compared to 2.7 -fold in full-term). These observations suggest that a heightened immune response to RSV infection may occur in preterm lambs to compensate for an initial deficit in baseline levels in the immature non-infected lung. This initial deficit, together with the increased viral load, the overall exaggerated response and altered activation state of the cells may contribute to the increased pathology observed.

\section{Conclusions}

In summary, the current study demonstrated that RSV infection of preterm lambs resulted in enhanced levels of pro-inflammatory mediators, including cytokines and chemokines. Lungs of RSV-infected preterm lambs, but not full-term lambs, had marked structural changes, as evidenced by epithelial thickening, increased PAS staining and increased caspase 3 staining in bronchioles and alveoli. Although the expression of caspase 3 suggests the activation of the apoptotic machinery as a result of viral infection of cells, the inefficient innate immune responses mediated in part by the phenotypically altered neutrophils and macrophages likely contribute to the enhanced disease pathology and severity. The similarities in the severity of RSV between lambs and humans in regards to viral susceptibility, clinical responses, lesions and immune responses highlight the utility of the pre-term lamb model to study pathogenesis of RSV. In addition, the ability to induce premature birth in lambs provides an excellent opportunity to study the mechanisms underlying the age-dependent susceptibility of human infants to RSV. Finally, the outbred nature of lambs is a useful characteristic to determine the genetic basis for susceptibility to, and re-infections with RSV.

\section{Abbreviations used in this paper}

IFN: interferon; IHC: immunohistochemistry; IL-: interleukin; IR: immunoreactivity; MCP: monocyte chemotactic protein (also called CCL2); MIP1-a (also called CCL3); PD-L1: programmed death ligand 1; RT-qPCR: reverse transcriptase quantitative polymerase chain reaction; RSV: respiratory syncytial virus; TNF-a: tumor necrosis factor $a$.

\section{Acknowledgements}

We thank the histology lab (Toni Christofferson, Jenny Groeltz-Thrush and Diane Gerjets) for technical support. This research was supported in part by $\mathrm{NIH}$ RO1 062787A.

\section{Author details}

${ }^{1}$ Department of Veterinary Pathology, College of Veterinary Medicine, lowa State University, Ames, IA 50011, USA. ²Medlmmune, LLC, One Medlmmune Way, Gaithersburg, MD 20878, USA.

\section{Authors' contributions}

FBS designed, performed the immunological experiments and data analysis for this study, and wrote the manuscript. JMG assisted in the design, performance and analysis of the real-time RT-PCR experiments and edited the manuscript. SK, ACP, and JS provided intellectual input and editorial assistance for the study, participated in the writing and editing of the manuscript, and provided funding for the project. MRA was the principal investigator who oversaw the project, performed the necropsy/tissue collection/lung tissue scoring, participated in the writing and editing of the manuscript, and provided intellectual input and funding for the project. All authors read and approved the final manuscript.

\section{Competing interests}

This work was supported in part by Medlmmune, LLC. SK, ACP and JS are employees of Medlmmune, LLC. FBS is supported by Medlmmune, LLC.

Received: 11 April 2011 Accepted: 9 August 2011

Published: 9 August 2011

\section{References}

1. Hall CB: Respiratory syncytial virus. 4 edition. Philadelphia: Saunders; 1998.

2. Nair H, Nokes DJ, Gessner BD, Dherani M, Madhi SA, Singleton RJ, O'Brien KL, Roca A, Wright PF, Bruce N, Chandran A, Theodoratou E, Sutanto A, Sedyaningsih ER, Ngama M, Munywoki PK, Kartasasmita C, Simoes EA, Rudan I, Weber MW, Campbell H: Global burden of acute lower respiratory infections due to respiratory syncytial virus in young children: a systematic review and meta-analysis. Lancet 2010, 375(9725):1545-1555.

3. Groothuis JR, Hoopes JM, Jessie VG: Prevention of serious respiratory syncytial virus-related illness. I: Disease pathogenesis and early attempts at prevention. Adv Ther 2011, 28(2):91-109.

4. Carbonell-Estrany X, Bont L, Doering G, Gouyon JB, Lanari M: Clinical relevance of prevention of respiratory syncytial virus lower respiratory tract infection in preterm infants born between 33 and 35 weeks gestational age. Eur J Clin Microbiol Infect Dis 2008, 27(10):891-899.

5. Boyce TG, Mellen BG, Mitchel EF Jr, Wright PF, Griffin MR: Rates of hospitalization for respiratory syncytial virus infection among children in medicaid. J Pediatr 2000, 137(6):865-870.

6. Groothuis JR, Hoopes JM, Hemming VG: Prevention of serious respiratory syncytial virus-related illness. II: Immunoprophylaxis. Adv Ther 2011, 28(2):110-125.

7. Varga SM, Braciale TJ: RSV-induced immunopathology: dynamic interplay between the virus and host immune response. Virology 2002, 295(2):203-207.

8. Durbin JE, Durbin RK: Respiratory syncytial virus-induced immunoprotection and immunopathology. Viral Immunol 2004, 17(3):370-380.

9. DeVincenzo JP, El Saleeby CM, Bush AJ: Respiratory syncytial virus load predicts disease severity in previously healthy infants. J Infect Dis 2005, 191(11):1861-1868.

10. Kim HW, Canchola JG, Brandt CD, Pyles G, Chanock RM, Jensen K, Parrott RH: Respiratory syncytial virus disease in infants despite prior administration of antigenic inactivated vaccine. Am J Epidemiol 1969, 89(4):422-434.

11. Kim HW, Leikin SL, Arrobio J, Brandt CD, Chanock RM, Parrott RH: Cellmediated immunity to respiratory syncytial virus induced by inactivated vaccine or by infection. Pediatr Res 1976, 10(1):75-78.

12. Meyerholz DK, Grubor B, Fach SJ, Sacco RE, Lehmkuhl HD, Gallup JM, Ackermann MR: Reduced clearance of respiratory syncytial virus infection in a preterm lamb model. Microbes Infect 2004, 6(14):1312-1319. 
13. Sow FB, Gallup JM, Meyerholz DK, Ackermann MR: Gene profiling studies in the neonatal ovine lung show enhancing effects of VEGF on the immune response. Dev Comp Immunol 2009, 33(6):761-771.

14. Gallup JM, Ackermann MR: The 'PREXCEL-Q Method' for qPCR. Int J Biomed Sci 2008, 4(4):273-293.

15. Sow FB, Gallup JM, Olivier A, Krishnan S, Patera AC, Suzich J, Ackermann MR: Respiratory syncytial virus is associated with an inflammatory response in lungs and architectural remodeling of lungdraining lymph nodes of newborn lambs. Am J Physiol Lung Cell Mol Physiol 2011, 300(1):L12-24.

16. Pfaffl MW: A new mathematical model for relative quantification in realtime RT-PCR. Nucleic Acids Res 2001, 29(9):e45.

17. Meyerholz DK, DeGraaff JA, Gallup JM, Olivier AK, Ackermann MR: Depletion of alveolar glycogen corresponds with immunohistochemical development of CD208 antigen expression in perinatal lamb lung. J Histochem Cytochem 2006, 54(11):1247-1253.

18. Johnson JE, Gonzales RA, Olson SJ, Wright PF, Graham BS: The histopathology of fatal untreated human respiratory syncytial virus infection. Mod Pathol 2007, 20(1):108-119.

19. Brandenburg AH, Neijens HJ, Osterhaus AD: Pathogenesis of RSV lower respiratory tract infection: implications for vaccine development. Vaccine 2001, 19(20-22):2769-2782.

20. Cutlip RC, Lehmkuhl HD: Lesions in lambs experimentally infected with bovine respiratory syncytial virus. Am J Vet Res 1979, 40(10):1479-1482.

21. Lehmkuhl HD, Cutlip RC: Experimental respiratory syncytial virus infection in feeder-age lambs. Am J Vet Res 1979, 40(12):1729-1730.

22. Lehmkuhl HD, Cutlip RC: Experimentally induced respiratory syncytial viral infection in lambs. Am J Vet Res 1979, 40(4):512-544.

23. Everard ML, Swarbrick A, Wrightham M, Mclntyre J, Dunkley C, James PD, Sewell HF, Milner AD: Analysis of cells obtained by bronchial lavage of infants with respiratory syncytial virus infection. Arch Dis Child 1994, 71(5):428-432.

24. Heidema J, Lukens MV, van Maren WW, van Dijk ME, Otten HG, van Vught AJ, van der Werff DB, van Gestel SJ, Semple MG, Smyth RL, Kimpen $J$, van Bleek GM: CD8+ T cell responses in bronchoalveolar lavage fluid and peripheral blood mononuclear cells of infants with severe primary respiratory syncytial virus infections. J Immunol 2007, 179(12):8410-8417.

25. Smith PK, Wang SZ, Dowling KD, Forsyth KD: Leucocyte populations in respiratory syncytial virus-induced bronchiolitis. J Paediatr Child Health 2001, 37(2):146-151.

26. Klebanoff SJ: Myeloperoxidase-halide-hydrogen peroxide antibacterial system. J Bacteriol 1968, 95(6):2131-2138.

27. Lehrer RI, Hanifin J, Cline MJ: Defective bactericidal activity in myeloperoxidase-deficient human neutrophils. Nature 1969, 223(5201):78-79.

28. Kitahara M, Eyre HJ, Simonian Y, Atkin CL, Hasstedt SJ: Hereditary myeloperoxidase deficiency. Blood 1981, 57(5):888-893.

29. Gordon S: Alternative activation of macrophages. Nat Rev Immunol 2003, 3(1):23-35.

30. Cunningham CK, MCMillan JA, Gross SJ: Rehospitalization for respiratory illness in infants of less than 32 weeks' gestation. Pediatrics 1991, 88(3):527-532.

31. Yuksel B, Greenough A: Birth weight and hospital readmission of infants born prematurely. Arch Pediatr Adolesc Med 1994, 148(4):384-388.

32. Medzhitov R, Janeway CA Jr: Innate immunity: the virtues of a nonclonal system of recognition. Cell 1997, 91(3):295-298.

33. Zeng R, Li C, Li N, Wei L, Cui Y: The role of cytokines and chemokines in severe respiratory syncytial virus infection and subsequent asthma. Cytokine 53(1):1-7.

34. Krishnan S, Halonen M, Welliver RC: Innate immune responses in respiratory syncytial virus infections. Viral Immunol 2004, 17(2):220-233.

35. Moore ML, Peebles RS Jr: Respiratory syncytial virus disease mechanisms implicated by human, animal model, and in vitro data facilitate vaccine strategies and new therapeutics. Pharmacol Ther 2006, 112(2):405-424.

36. Wright WC Jr, Ank BJ, Herbert J, Stiehm ER: Decreased bactericidal activity of leukocytes of stressed newborn infants. Pediatrics 1975, 56(4):579-584.

37. Cairo MS: Neonatal neutrophil host defense. Prospects for immunologic enhancement during neonatal sepsis. Am J Dis Child 1989, 143(1):40-46.

38. Carr R: Neutrophil production and function in newborn infants. $\mathrm{Br}\rfloor$ Haematol 2000, 110(1):18-28.
39. Mosser DM: The many faces of macrophage activation. J Leukoc Biol 2003, 73(2):209-212.

40. Welliver TP, Garofalo RP, Hosakote Y, Hintz KH, Avendano L, Sanchez K, Velozo L, Jafri H, Chavez-Bueno S, Ogra PL, McKinney L, Reed JL, Welliver RC Sr: Severe human lower respiratory tract illness caused by respiratory syncytial virus and influenza virus is characterized by the absence of pulmonary cytotoxic lymphocyte responses. J Infect Dis 2007, 195(8):1126-1136.

41. Braciale TJ: Respiratory syncytial virus and T cells: interplay between the virus and the host adaptive immune system. Proc Am Thorac Soc 2005, 2(2):141-146.

42. Chi B, Dickensheets HL, Spann KM, Alston MA, Luongo C, Dumoutier L, Huang J, Renauld JC, Kotenko SV, Roederer M, Beeler JA, Donnelly RP, Collins PL, Rabin RL: Alpha and lambda interferon together mediate suppression of CD4 T cells induced by respiratory syncytial virus. J Virol 2006, 80(10):5032-5040.

43. Chang J, Braciale TJ: Respiratory syncytial virus infection suppresses lung CD8+ T-cell effector activity and peripheral CD8+ T-cell memory in the respiratory tract. Nat Med 2002, 8(1):54-60.

44. Roe MF, Bloxham DM, White DK, Ross-Russell RI, Tasker RT, O'Donnell DR: Lymphocyte apoptosis in acute respiratory syncytial virus bronchiolitis. Clin Exp Immunol 2004, 137(1):139-145.

45. Barber DL, Wherry EJ, Masopust D, Zhu B, Allison JP, Sharpe AH, Freeman GJ, Ahmed R: Restoring function in exhausted CD8 T cells during chronic viral infection. Nature 2006, 439(7077):682-687.

46. Day CL, Kaufmann DE, Kiepiela P, Brown JA, Moodley ES, Reddy S, Mackey EW, Miller JD, Leslie AJ, DePierres C, Mncube Z, Duraiswamy J, Zhu B, Eichbaum Q, Altfeld M, Wherry EJ, Coovadia HM, Goulder PJ, Klenerman P, Ahmed R, Freeman GJ, Walker BD: PD-1 expression on HIVspecific $T$ cells is associated with T-cell exhaustion and disease progression. Nature 2006, 443(7109):350-354.

47. Trautmann L, Janbazian L, Chomont N, Said EA, Gimmig S, Bessette B, Boulassel MR, Delwart E, Sepulveda H, Balderas RS, Routy JP, Haddad EK, Sekaly RP: Upregulation of PD-1 expression on HIV-specific CD8+ T cells leads to reversible immune dysfunction. Nat Med 2006, 12(10):1198-1202.

48. Petrovas C, Casazza JP, Brenchley JM, Price DA, Gostick E, Adams WC, Precopio ML, Schacker T, Roederer M, Douek DC, Koup RA: PD-1 is a regulator of virus-specific CD8+ T cell survival in HIV infection. J Exp Med 2006, 203(10):2281-2292.

doi:10.1186/1465-9921-12-106

Cite this article as: Sow et al:: Respiratory syncytial virus infection is associated with an altered innate immunity and a heightened proinflammatory response in the lungs of preterm lambs. Respiratory Research 2011 12:106.

\section{Submit your next manuscript to BioMed Central and take full advantage of:}

- Convenient online submission

- Thorough peer review

- No space constraints or color figure charges

- Immediate publication on acceptance

- Inclusion in PubMed, CAS, Scopus and Google Scholar

- Research which is freely available for redistribution

Submit your manuscript at www.biomedcentral.com/submit
C) Biomed Central 